\title{
Strength Assessment of Broken Rock Postgrouting Reinforcement Based on Initial Broken Rock Quality and Grouting Quality
}

\author{
Hongfa Xu, ${ }^{1}$ Hansheng Geng, ${ }^{1}$ Feng Chen, ${ }^{2}$ Xiao Chen, ${ }^{1}$ and Liangliang Qi ${ }^{1}$ \\ ${ }^{1}$ State Key Laboratory of Disaster Prevention \& Mitigation of Explosion \& Impact, PLA University of Science and Technology, \\ Nanjing, Jiangsu 210007, China \\ ${ }^{2}$ Nanjing Army Command College, Nanjing, Jiangsu 210045, China
}

Correspondence should be addressed to Hansheng Geng; genghansheng@163.com

Received 29 November 2016; Accepted 15 February 2017; Published 15 March 2017

Academic Editor: Francesco Pesavento

Copyright (C) 2017 Hongfa Xu et al. This is an open access article distributed under the Creative Commons Attribution License, which permits unrestricted use, distribution, and reproduction in any medium, provided the original work is properly cited.

\begin{abstract}
To estimate postgrouting rock mass strength growth is important for engineering design. In this paper, using self-developed indoor pressure-grouting devices, 19 groups of test cubic blocks were made of the different water cement ratio grouting into the broken rock of three kinds of particle sizes. The shear strength parameters of each group under different conditions were tested. Then this paper presents a quantitative calculation method for predicting the strength growth of grouted broken rock. Relational equations were developed to investigate the relationship between the growth rates of uniaxial compressive strength (UCS), absolute value of uniaxial tensile strength (AUTS), internal friction angle, and cohesion for post- to pregrouting broken rock based on MohrCoulomb strength criterion. From previous test data, the empirical equation between the growth rate of UCS and the ratio of the initial rock mass UCS to the grout concretion UCS has been determined. The equations of the growth rates of the internal friction coefficient and UCS for grouting broken rock with rock mass rating (RMR) and its increment have been established. The calculated results are consistent with the experimental results. These observations are important for engineered design of grouting reinforcement for broken rock mass.
\end{abstract}

\section{Introduction}

Geotechnical and underground engineering are often in complex geological environments where broken rock mass is one of the frequently encountered medium. In such cases, grouting is usually used for reinforcement, which can well improve the condition, integrity, and the bearing capacity (Lombardi [1], Glossop [2]). For such engineering, when designed or calculated by the engineers, it is an important problem to accurately determine the mechanical model and the parameters of the grouting broken rock mass. For example, Li et al. [3] converted the mechanical parameters of the original rock to determine the parameters of grouting reinforcement in the mechanical analysis of broken rock mass section in a tunnel construction design; Youn and Tonon [4] used parameters obtained from the experimental results of grouting layer of Texas Gulf Coast Soil (Sellountou [5]) to study the behavior of postgrouted drilled shafts at the Brazo River Bridge; these two methods of taking parameters will inevitably lead to relatively large error. In the support design of No. 1 Coal Mine, Yangquan Coal Industry Group Co. Ltd., Wang et al. [6] considered the grouting layer as a homogeneous medium and combined the linear elastic model with the Mohr-Coulomb criterion to simulate the support model; the same method was used in the analysis for undersea tunnel stability and in prediction of displacement of tunnel surface (He and Wang [7], Sharghi et al. [8]); Dai et al. [9] used the Kelvin-Hooke model to characterise the mechanical model of the grouting reinforced bodies in broken rock mass; in the study of support in a tunnel, Dai et al. [10] combined the elastic-plastic model with the D$\mathrm{P}$ criterion for the grouting layer; the most critical step in these studies was to determine the mechanical parameters (strength, modulus, friction angle, and cohesion) of the 
model by means of field tests rather than by empirical formulas or any specifications.

From the above, it can be seen that the research on the determination of mechanical models and parameters of grouting broken rock mass is still in the initial stage and it is difficult to determine the parameters quantitatively. The main obstacle lies in the heterogeneity of broken rock mass and the complexity of fracture structure (ISRM [11]). For the support design of underground engineering, slope engineering, and foundation pits in broken rock mass, the unpredictability of the mechanics parameters of the postgrouting broken rock mass makes the design and numerical analysis result in great errors.

At present, study of the mechanics model, parameters, and effect prediction of postgrouting broken rock mass is relatively sparse. Some of them are typical; for example, through the mechanical experiments and borehole expansion test during the grouting process, Kikuchi et al. [12] found that the mechanical properties of the broken rock tend to become uniform after grouting; based on the experimental data of Quantai Coal Mine and damage mechanics, the constitutive model of postgrouting broken rock mass was established by Yang and Zhang [13]; Butrón et al. [14] performed laboratory tests, including fall-cone, unconfined compression, and triaxial tests, to determine the dynamic and quasi-static mechanical model of slurry consolidation body; Zolfaghari et al. [15] applied Q system into estimation of the change of elastic modulus before and after grouting through field test at the Bakhtiari dam site; experimental results showed that the $\mathrm{Q}$ system can be used as a practical and undemanding method in evaluation of rock mass quality by the grouting treatment, while there is no research on estimating parameters of grouting reinforcement by GSI index or RMR; through neural networks, Tinoco et al. [16] analyze a large number of experimental data to predict the strength of grouting reinforced rock mass, which is timeconsuming and not universal; Akan et al. [17] studied the fitting model of predicting the compressive strength of grouting body by nonlinear regression of experimental data; Zhou [18] calculated the relationship between grouting parameters and bearing capacity of pile by numerical simulation. In general, the grouting broken rock mass is still in the exploratory stage in the study of mechanical model and parameters; qualitative research is more, while quantitative research is less and onesided in this field.

In view of these deficiencies, this paper focuses on broken rock mass within rock mass classes IV (poor) and V (very poor) of the classification scheme based on the rock mass rating (RMR) system (Bieniawski et al. [19, 20]). Through selfdeveloped laboratory pressure-grouting device and the direct shear apparatus, a large number of uniaxial compression test and direct shear test have been carried out on specimen of slurry consolidation bodies and broken rock mass preand postgrouting reinforcement; relationship between the growth rates of the uniaxial compression strength (UCS), absolute value of uniaxial tensile strength (AUTS), internal friction coefficient, and cohesion for pre- and postgrouting reinforcement are derived by using the Mohr-Coulomb strength criterion; combined with the empirical formulae of

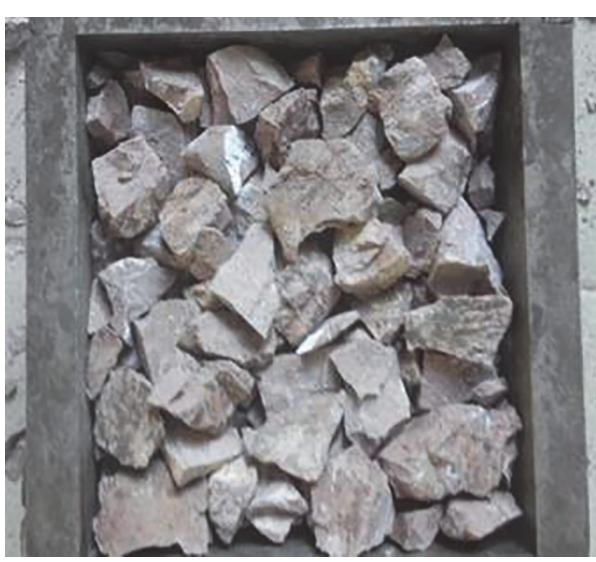

FIGURE 1: Medium particle broken rock in the steel mold.

Aydan et al. [21, 22], mathematical calculation process and curves for each growth rate of these four parameters and rock mass rating (RMR) are presented in Sections 3-7, with the UCS of grout concretion into account. Through comparison, it indicates that the experimental data are in good agreement with the equation curve. The RMR-based method to predict the mechanical parameters of broken rock mass grouting reinforcement and the derived equations can be used effectively for engineering design of various broken rock mass engineering and for the determination of parameters in numerical analysis, which will reduce the calculation error. Based on previous studies [23, 24], RMR and Mohr-Coulomb parameters can be converted into GSI index, Q system, and Hoek-Brown parameters by further research.

\section{Shear Strength Tests on the Concretion of Grouting Reinforced Broken Rock}

2.1. Test Method. We carried out the shear strength test of grouting reinforced bodies of broken rock mass. The test methods are as follows.

(1) Simulate Broken Rock Mass with Crushed Stone (or Broken Rock). The rock is weak weathered limestone from the Mengmu quarry in Nanjing, Jiangsu.

(2) Broken Degree of the Rock Mass Is Represented by Different Particle Size of Broken Rock. We used broken rock with three kinds of particle size, namely, fine (F) $0 \sim 2 \mathrm{~cm}$, medium (M) $2 \sim 4 \mathrm{~cm}$, and coarse (R) $4 \sim 6 \mathrm{~cm}$. Figure 1 shows that the medium particle broken rock is placed in the steel mold.

(3) Test Blocks Making Equipment. The self-developed pressure-grouting device is used in the laboratory as shown in Figure 2. The device is composed of three parts, which are the sealing steel mold, the sealing steel pressure pail containing grout, and the air compressor. The test procedures are the following:

(i) Placing broken rock into the sealing steel mold

(ii) Pouring grout mixing cement with water into the pressure pail 
TABLE 1: Test schemes and groups.

\begin{tabular}{|c|c|c|c|c|c|c|c|}
\hline \multirow[t]{2}{*}{$\begin{array}{l}\text { Scheme } \\
\text { number }\end{array}$} & \multirow[t]{2}{*}{$\begin{array}{l}\text { Broken rock } \\
\text { particle size }\end{array}$} & \multicolumn{5}{|c|}{$\begin{array}{c}\text { Group number ( } 5 \text { test blocks in each } \\
\text { group) } \\
\text { Water cement ratio }\end{array}$} & \multirow[t]{2}{*}{ Test purpose } \\
\hline & & 0.7 & 0.9 & 1.1 & 1.3 & 2.5 & \\
\hline I & - & $\mathrm{C} 07$ & $\mathrm{C} 09$ & C11 & $\mathrm{C} 13$ & - & $\begin{array}{l}\text { To test the shear strength of } \\
\text { grout concretion }\end{array}$ \\
\hline \multirow{3}{*}{ II } & $\mathrm{F}$ & - & - & - & - & OF & \multirow{3}{*}{$\begin{array}{l}\text { To test the shear strength of } \\
\text { the original broken rock }\end{array}$} \\
\hline & M & - & - & - & - & OM & \\
\hline & $\mathrm{R}$ & - & - & - & - & OR & \\
\hline III & $\mathrm{F}$ & F07 & F09 & F11 & F13 & - & $\begin{array}{l}\text { To test the shear strength of } \\
\text { fine particle broken rock } \\
\text { grouting reinforced } \\
\text { concretion }\end{array}$ \\
\hline IV & M & M07 & M09 & M11 & M13 & - & $\begin{array}{l}\text { To test the shear strength of } \\
\text { medium particle broken } \\
\text { rock grouting reinforced } \\
\text { concretion }\end{array}$ \\
\hline $\mathrm{V}$ & $\mathrm{R}$ & $\mathrm{R} 07$ & R09 & R11 & R13 & - & $\begin{array}{l}\text { To test the shear strength of } \\
\text { coarse particle broken rock } \\
\text { grouting reinforced } \\
\text { concretion }\end{array}$ \\
\hline
\end{tabular}

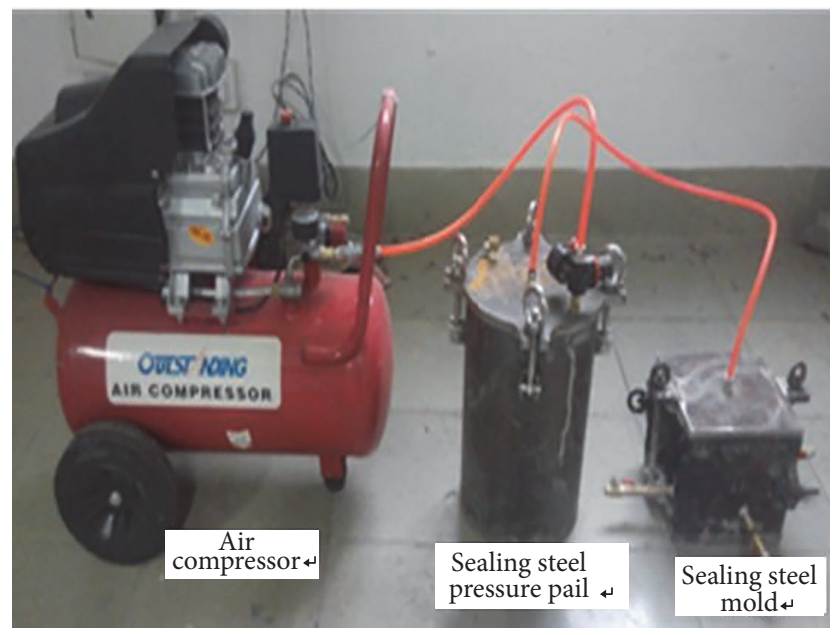

FIGURE 2: Grouting test device.

(iii) Starting the air compressor to increase pressure of the pail and grouting into the sealing steel mold filled broken rock

(iv) Discharging excess grout from the outlet and maintaining $0.3 \mathrm{MPa}$ of the grouting pressure for 5 minutes

(v) Demolding for the test blocks after condensation hardening for 24 hours

The test block is the cube of $150 \times 150 \times 150 \mathrm{~mm}^{3}$. The typical test blocks are shown in Figure 3.

(4) Test Schemes. The purpose of this experiment is to analyze the influence of Initial Rock Mass Quality and Grouting Quality on the strength of broken rock grouting reinforced concretion. From the research results of literature $[25,26]$, strength growth rate of broken rock mass is closely related

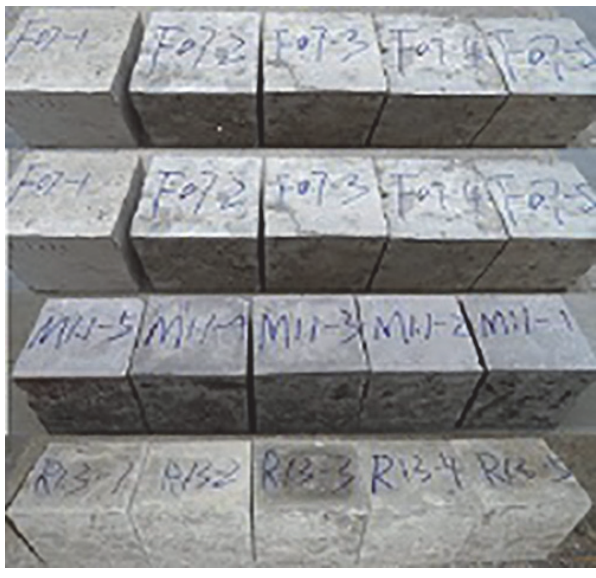

FIGURE 3: Typical test blocks.

to the strength of the original rock and the strength of grout concretions. The five test schemes are developed for this experiment. All 95 test blocks are made in 19 groups (each group has five), as shown in Table 1.

(i) In scheme I, there are 4 groups to test the shear strength of pure cement grout concretion under different water cement ratio.

(ii) In scheme II, there are 3 groups to test the shear strength of pure broken rock using a very high water cement ratio grouting reinforced concretion, which considered grout cementing action is very small.

(iii) In scheme III, there are 4 groups to test the shear strength of fine particle broken rock grouting reinforced concretion under different water cement ratio.

(iv) In scheme IV, there are 4 groups to test the shear strength of medium particle broken rock grouting 
TABLE 2: Normal stress and peak shear strength.

\begin{tabular}{|c|c|c|c|c|c|c|c|}
\hline \multirow{3}{*}{ Scheme number } & \multirow{3}{*}{ Group number } & \multicolumn{6}{|c|}{ Stress/MPa } \\
\hline & & \multirow{2}{*}{ Normal or Shear } & \multicolumn{5}{|c|}{ Test block number } \\
\hline & & & 1 & 2 & 3 & 4 & 5 \\
\hline \multirow{8}{*}{ I } & \multirow{2}{*}{$\mathrm{C} 07$} & $\sigma_{n}$ & 1.333 & 2.444 & 3.111 & 3.778 & 4.444 \\
\hline & & $\tau_{m}$ & 3.504 & 5.182 & 5.782 & 6.493 & 7.124 \\
\hline & \multirow{2}{*}{ C09 } & $\sigma_{n}$ & 1.111 & 1.778 & 2.444 & 3.111 & 3.778 \\
\hline & & $\tau_{m}$ & 2.562 & 3.131 & 3.891 & 4.257 & 4.666 \\
\hline & \multirow{2}{*}{ C11 } & $\sigma_{n}$ & 0.889 & 1.556 & 2.222 & 2.889 & 3.556 \\
\hline & & $\tau_{m}$ & 2.049 & 2.486 & 2.753 & 3.142 & 3.631 \\
\hline & \multirow{2}{*}{$\mathrm{C} 13$} & $\sigma_{n}$ & 0.889 & 1.332 & 1.776 & 2.220 & 2.664 \\
\hline & & $\tau_{m}$ & 1.637 & 1.703 & 1.851 & 1.977 & 2.149 \\
\hline \multirow{6}{*}{ II } & \multirow{2}{*}{ OF } & $\sigma_{n}$ & 0.889 & 1.332 & 1.776 & 2.220 & 2.664 \\
\hline & & $\tau_{m}$ & 0.650 & 0.863 & 1.030 & 1.157 & 1.419 \\
\hline & \multirow{2}{*}{$\mathrm{OM}$} & $\sigma_{n}$ & 0.889 & 1.332 & 1.776 & 2.220 & 2.664 \\
\hline & & $\tau_{m}$ & 1.006 & 1.367 & 1.588 & 1.760 & 1.929 \\
\hline & \multirow{2}{*}{ OR } & $\sigma_{n}$ & 0.889 & 1.332 & 1.776 & 2.220 & 2.664 \\
\hline & & $\tau_{m}$ & 1.677 & 1.851 & 2.180 & 2.573 & 2.782 \\
\hline \multirow{8}{*}{ III } & \multirow{2}{*}{ F07 } & $\sigma_{n}$ & 1.111 & 2.222 & 3.333 & 4.444 & 5.555 \\
\hline & & $\tau_{m}$ & 2.978 & 3.690 & 4.480 & 5.017 & 5.603 \\
\hline & \multirow{2}{*}{ F09 } & $\sigma_{n}$ & 1.111 & 2.000 & 2.889 & 3.778 & 4.444 \\
\hline & & $\tau_{m}$ & 2.553 & 2.880 & 3.697 & 3.848 & 4.352 \\
\hline & \multirow{2}{*}{ F11 } & $\sigma_{n}$ & 0.889 & 1.556 & 2.222 & 2.889 & 3.556 \\
\hline & & $\tau_{m}$ & 2.153 & 2.477 & 2.953 & 3.275 & 3.530 \\
\hline & \multirow{2}{*}{ F13 } & $\sigma_{n}$ & 0.889 & 1.333 & 1.778 & 2.222 & 2.667 \\
\hline & & $\tau_{m}$ & 2.045 & 2.314 & 2.603 & 2.757 & 2.963 \\
\hline \multirow{8}{*}{ IV } & \multirow{2}{*}{ M07 } & $\sigma_{n}$ & 1.333 & 2.222 & 3.111 & 4.000 & 4.889 \\
\hline & & $\tau_{m}$ & 3.512 & 4.233 & 4.746 & 5.384 & 6.032 \\
\hline & \multirow{2}{*}{ M09 } & $\sigma_{n}$ & 0.888 & 1.332 & 2.222 & 3.111 & 4.000 \\
\hline & & $\tau_{m}$ & 2.688 & 3.067 & 3.557 & 4.256 & 4.736 \\
\hline & \multirow{2}{*}{ M11 } & $\sigma_{n}$ & 0.888 & 1.776 & 2.664 & 3.552 & 4.440 \\
\hline & & $\tau_{m}$ & 2.319 & 3.007 & 3.669 & 4.236 & 4.588 \\
\hline & \multirow{2}{*}{ M13 } & $\sigma_{n}$ & 0.667 & 1.334 & 2.222 & 2.889 & 3.556 \\
\hline & & $\tau_{m}$ & 2.220 & 2.575 & 3.108 & 3.735 & 3.923 \\
\hline \multirow{8}{*}{$\mathrm{V}$} & R07 & $\sigma_{n}$ & 1.778 & 2.667 & 4.000 & 5.333 & 6.667 \\
\hline & & $\tau_{m}$ & 4.438 & 5.034 & 6.140 & 7.074 & 8.769 \\
\hline & R09 & $\sigma_{n}$ & 1.333 & 2.222 & 3.111 & 4.000 & 4.889 \\
\hline & & $\tau_{m}$ & 3.538 & 3.958 & 4.876 & 5.475 & 6.433 \\
\hline & R11 & $\sigma_{n}$ & 1.333 & 1.778 & 2.222 & 3.111 & 4.000 \\
\hline & KII & $\tau_{m}$ & 3.003 & 3.516 & 3.879 & 4.382 & 5.285 \\
\hline & R13 & $\sigma_{n}$ & 1.556 & 2.000 & 2.444 & 2.889 & 3.333 \\
\hline & & $\tau_{m}$ & 3.083 & 3.366 & 4.035 & 4.264 & 4.488 \\
\hline
\end{tabular}

reinforced concretion under different water cement ratio.

(v) In scheme $\mathrm{V}$, there are 4 groups to test the shear strength of coarse particle broken rock grouting reinforced concretion under different water cement ratio.

(5) Shear Strength Test. The shear strength test can be carried out on the blocks cured for 28 days using the YZW100 direct shear apparatus.

2.2. Test Results. There are five test blocks in each group. Each test block is placed horizontally in direct shear apparatus. A constant vertical stress (or normal stress $\sigma_{n}$ ) is applied on block first, then a horizontal stress (or shear stress $\tau$ ) is applied, and then shear displacement increases with shear stress varying until failure. The shear stress-displacement curve can be obtained. A constant normal stress is applied gradually from small to large on each block in each group. To prevent the normal stress crushing blocks, each group maximal normal stress must be less than UCS. The typical shear stress-displacement curves are shown in Figure 4.

From shear stress-displacement curve of each test block, the peak shear strength $\tau_{m}$ and the corresponding normal stress $\sigma_{n}$ are obtained, as Table 2 shows.

Suppose the shear strength of test block meets the MohrCoulomb strength criterion. Then the relation between the 


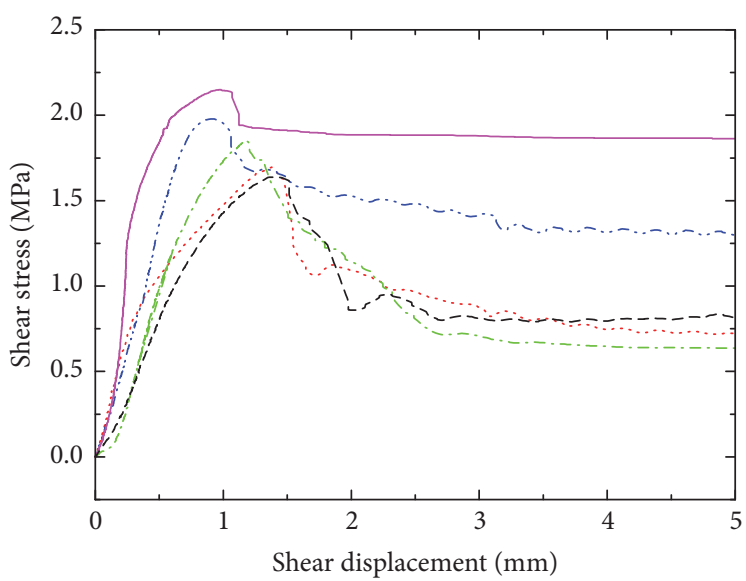

- - - Normal stress $0.889 \mathrm{MPa} \quad$..... Normal stress $2.220 \mathrm{MPa}$

..... Normal stress $1.332 \mathrm{MPa}$

-..- Normal stress $1.776 \mathrm{MPa}$

(a) Group $\mathrm{C} 13$

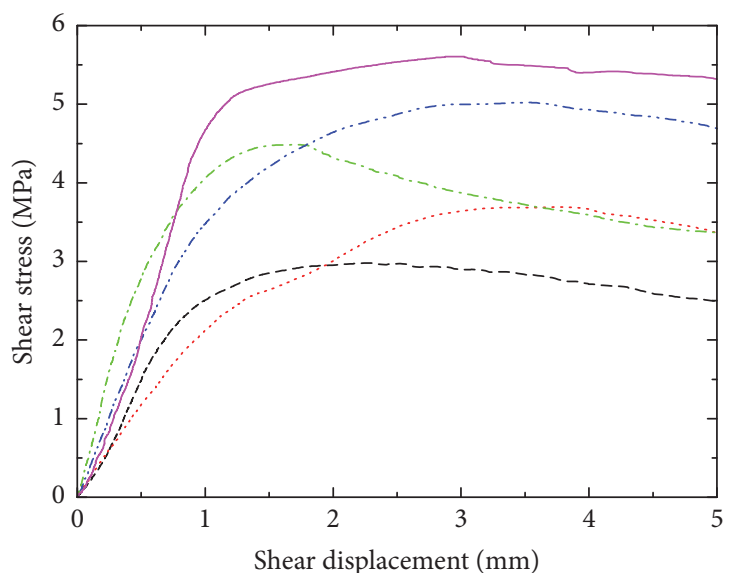

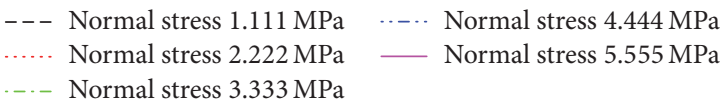

(c) Group F07

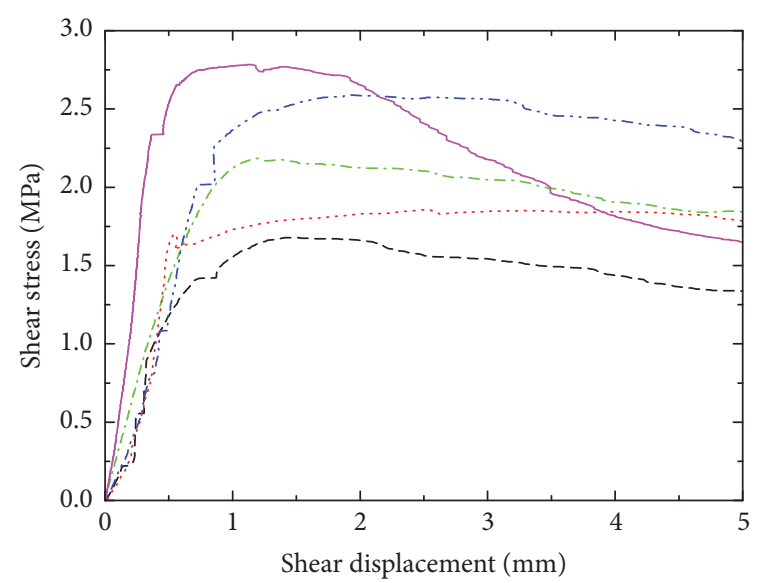

--- Normal stress $0.889 \mathrm{MPa} \quad$..... Normal stress $2.220 \mathrm{MPa}$ Normal stress $1.332 \mathrm{MPa} \quad$ Normal stress $2.664 \mathrm{MPa}$ -.. Normal stress $1.776 \mathrm{MPa}$

(b) Group OR

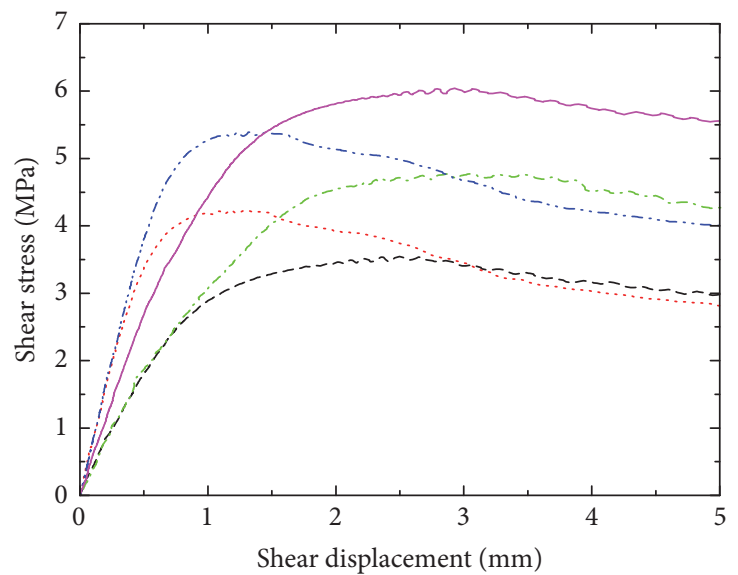

- - - Normal stress 1.333 MPa -.... Normal stress 4.000 MPa Normal stress $2.222 \mathrm{MPa} \quad$ Normal stress $4.889 \mathrm{MPa}$ -.. Normal stress $3.111 \mathrm{MPa}$

(d) Group M07

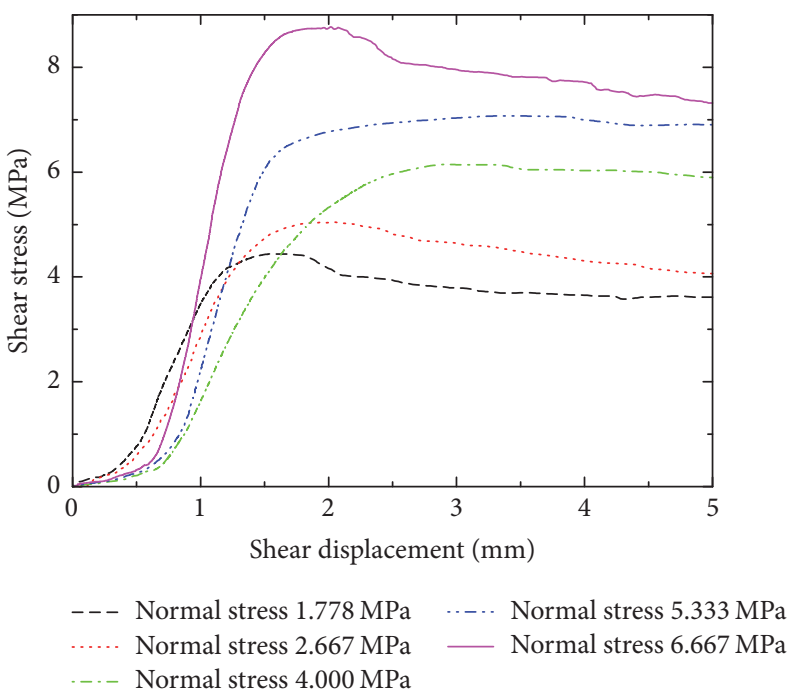

(e) Group R07

FIgURE 4: Typical shear stress-displacement curves. 
TABLE 3: Each group's shear strength parameter.

\begin{tabular}{|c|c|c|c|c|}
\hline \multirow{2}{*}{ Scheme number } & \multirow{2}{*}{ Group number } & \multicolumn{2}{|c|}{ Shear strength parameter } & \multirow{2}{*}{$R^{2}$ correlation coefficient } \\
\hline & & $c / \mathrm{MPa}$ & $f=\tan \varphi$ & \\
\hline \multirow{4}{*}{ I } & $\mathrm{C} 07$ & 2.150 & 1.147 & 0.9867 \\
\hline & C09 & 1.746 & 0.800 & 0.9815 \\
\hline & $\mathrm{C} 11$ & 1.539 & 0.573 & 0.9917 \\
\hline & $\mathrm{C} 13$ & 1.344 & 0.292 & 0.9819 \\
\hline \multirow{3}{*}{ II } & OF & 0.291 & 0.413 & 0.9884 \\
\hline & $\mathrm{OM}$ & 0.634 & 0.504 & 0.9702 \\
\hline & OR & 1.039 & 0.661 & 0.9850 \\
\hline \multirow{4}{*}{ III } & F07 & 2.381 & 0.592 & 0.9945 \\
\hline & F09 & 1.930 & 0.540 & 0.9642 \\
\hline & F11 & 1.694 & 0.533 & 0.9857 \\
\hline & F13 & 1.625 & 0.513 & 0.9874 \\
\hline \multirow{4}{*}{ IV } & M07 & 2.616 & 0.696 & 0.9958 \\
\hline & M09 & 2.140 & 0.658 & 0.9958 \\
\hline & M11 & 1.834 & 0.649 & 0.9865 \\
\hline & M13 & 1.782 & 0.623 & 0.9880 \\
\hline \multirow{4}{*}{$\mathrm{V}$} & R07 & 2.759 & 0.864 & 0.9833 \\
\hline & R09 & 2.299 & 0.817 & 0.9862 \\
\hline & R11 & 1.999 & 0.809 & 0.9872 \\
\hline & $\mathrm{R} 13$ & 1.930 & 0.792 & 0.9697 \\
\hline
\end{tabular}

peak shear strength $\left(\tau_{m}\right)$ and normal stress $\left(\sigma_{n}\right)$ on each group test should satisfy the following:

$$
\tau_{m}=\sigma_{n} \tan \varphi+c=\sigma_{n} f+c,
$$

where $c$ is the cohesion; $\varphi$ is the internal friction angle; $f$ is the internal friction coefficient; $\sigma_{n}$ is the normal stress acting on the failure plane; and $\tau_{m}$ is the maximum shear stress acting on the failure plane.

From Table 2, we can draw the strength test curve of each group; see Figure 5. The shear strength parameters of the each group test can be obtained using linear regression method; see Table 3 .

\section{Strength Growth of Postgrouting Broken Rock Mass}

In this paper, the following assumptions apply for broken rock mass:

(i) The rock mass is cut by several structural features, which form fractured massive, cataclastic, or scattered textures.

(ii) Rock mass strength is determined using the RMR classification system.

(iii) The broken rock mass is class IV or V, and the RMR's value is less than 25 .

(iv) Rock mass strength satisfies the Mohr-Coulomb strength criterion for low stress levels.

(v) Grouting improves the rock mass quality, leading to an increase in $R M R(\triangle R M R)$.
The Mohr-Coulomb criterion is one of the most trusted and widely used linear strength criteria for soils and rocks. Jaeger et al. [27] define the criterion as follows:

$$
\sigma_{1}=\frac{1+\sin \varphi}{1-\sin \varphi} \sigma_{3}+\frac{2 c \cos \varphi}{1-\sin \varphi}
$$

where $\sigma_{1}$ is the maximum principal stress in failure and $\sigma_{3}$ is the minimum principal stress in failure.

Expressions of the relationships between rock mass strength parameters are determined as follows:

$$
c=\frac{1}{2} \sqrt{S_{c} S_{t}}
$$

where $S_{c}$ is the uniaxial compressive strength (UCS) and $S_{t}$ is the absolute value of uniaxial tensile strength (AUTS).

$$
\begin{gathered}
f=\tan \varphi=\frac{S_{c}-S_{t}}{2 \sqrt{S_{c} S_{t}}} \\
\alpha=\frac{S_{t}}{S_{c}}=\frac{1-\sin \varphi}{1+\sin \varphi},
\end{gathered}
$$

where $\alpha$ is the ratio of the AUTS to the UCS.

The growth rates of each factor are determined as follows.

(i) The growth rate of UCS is expressed as

$$
\xi_{c}=\frac{\Delta S_{c}}{S_{c b}}=\frac{S_{c a}-S_{c b}}{S_{c b}}
$$

where $\xi_{c}$ is the UCS growth rate; $\Delta S_{c}$ is the growth value of UCS; $S_{c b}$ is the UCS of pregrouting broken rock; $S_{c a}$ is the UCS of post-grouting broken rock. 


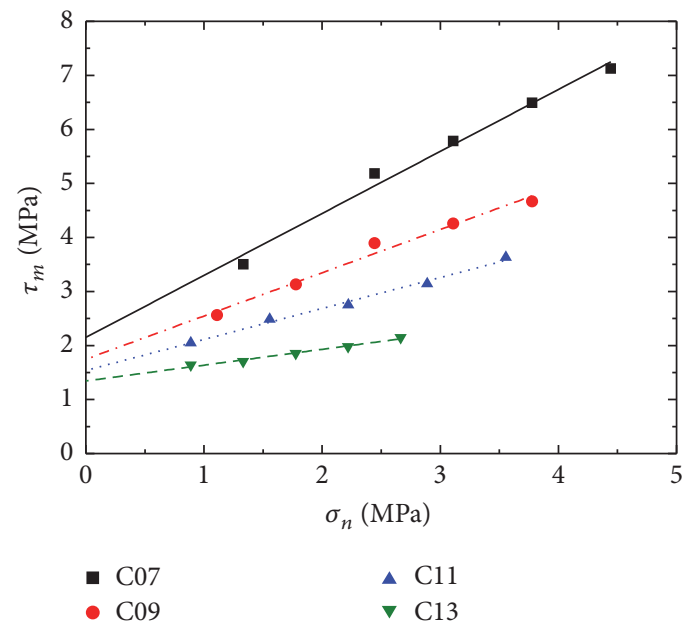

(a) Scheme I

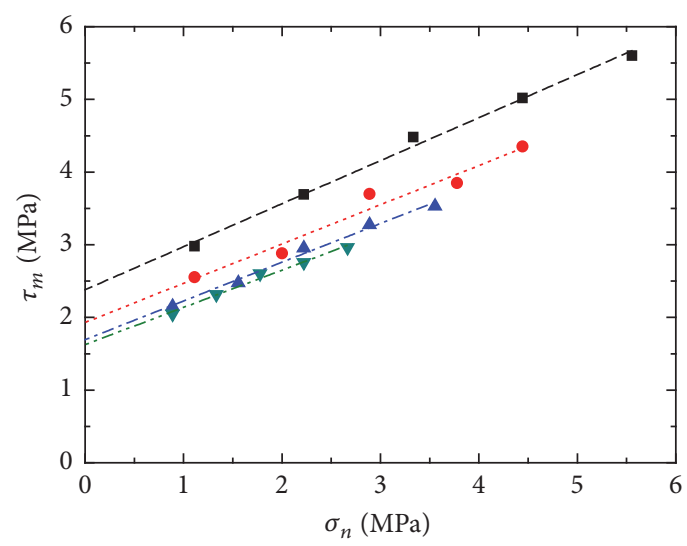

- $\mathrm{F} 07$

- F09

A F11

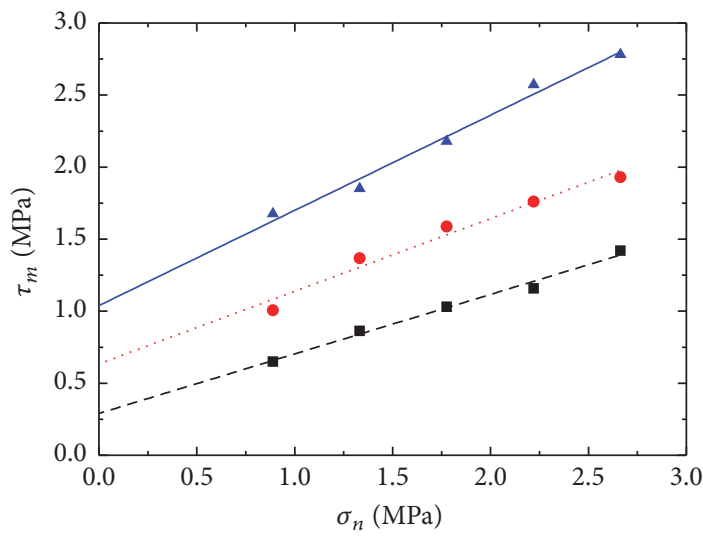

- $\mathrm{OF}$

$\triangle \mathrm{OR}$

- $\mathrm{OM}$

(b) Scheme II

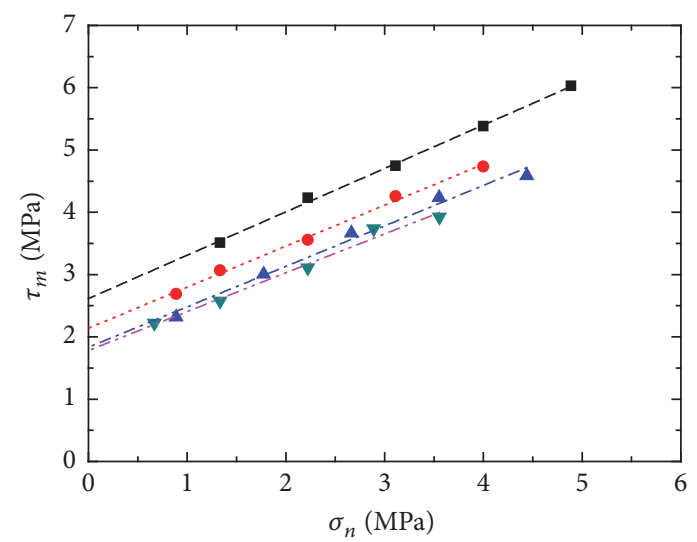

- M07

- M11

- M09

V M13

(d) Scheme IV

(c) Scheme III

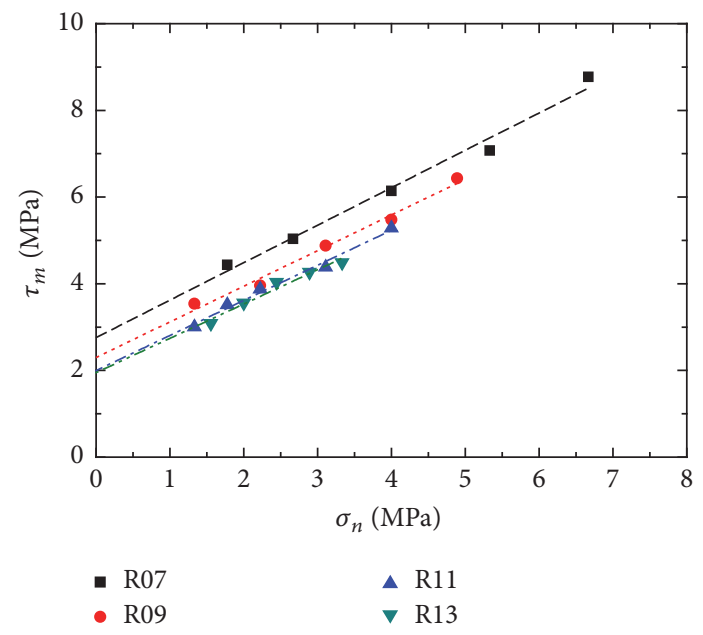

(e) Scheme IV

Figure 5: Shear strength curves. 
(ii) The absolute value of UTS growth rate is expressed as

$$
\xi_{t}=\frac{\Delta S_{t}}{S_{t b}}=\frac{S_{t a}-S_{t b}}{S_{t b}},
$$

where $\xi_{t}$ is the AUTS growth rate; $\Delta S_{t}$ is the growth value of AUTS; $S_{t b}$ is the AUTS of pregrouting broken rock; $S_{t a}$ is the AUTS of postgrouting broken rock.

(iii) The growth rate of cohesion is written as

$$
\xi_{\mathrm{coh}}=\frac{\Delta c}{c_{b}}=\frac{c_{a}-c_{b}}{c_{b}}
$$

where $\xi_{\text {coh }}$ is the cohesion growth rate; $\Delta c$ is the growth value of the cohesion; $c_{b}$ is the cohesion of pregrouting broken rock; $c_{a}$ is the cohesion of post-grouting broken rock.

(iv) The growth rate of internal friction coefficient is defined as

$$
\xi_{f}=\frac{\Delta f}{f_{b}}=\frac{f_{a}-f_{b}}{f_{b}},
$$

where $\xi_{f}$ is the growth rate of internal friction coefficient; $\Delta f$ is the growth value of internal friction coefficient; $f_{b}$ is internal friction coefficient of pregrouting broken rock; $f_{a}$ is internal friction coefficient of postgrouting broken rock.

By substituting (3) into (8), the relationships between the growth rate of cohesion and the growth rates of UCS and AUTS can be determined:

$$
\xi_{\text {coh }}=\frac{\sqrt{S_{c a} S_{t a}}}{\sqrt{S_{c b} S_{t b}}}-1=\sqrt{\left(\xi_{c}+1\right)\left(\xi_{t}+1\right)}-1 .
$$

Equation (10) can also be expressed as

$$
\xi_{t}=\frac{\left(\xi_{\mathrm{coh}}+1\right)^{2}}{\xi_{c}+1}-1 .
$$

Similarly, by substituting (4) into (9), the relationships between the growth rate of internal friction coefficient and the growth rates of cohesion, UCS, and AUTS can be determined:

$$
\begin{aligned}
\xi_{f} & =\frac{S_{c a}-S_{t a}}{S_{c b}-S_{t b}} \cdot \sqrt{\frac{S_{c b} S_{t b}}{S_{c a} S_{t a}}}-1 \\
& =\left(\xi_{c}+1\right) \frac{1-\alpha_{a}}{1-\alpha_{b}} \cdot \frac{1}{\sqrt{\left(\xi_{c}+1\right)\left(\xi_{t}+1\right)}}-1 \\
& =\frac{k\left(\xi_{c}+1\right)}{\xi_{\text {coh }}+1}-1,
\end{aligned}
$$

where $\alpha_{b}$ is the ratio of the AUTS to the UCS of pregrouting broken rock; $\alpha_{a}$ is the ratio of the AUTS to the UCS of postgrouting broken rock; and

$$
k=\frac{1-\alpha_{a}}{1-\alpha_{b}}=\frac{\sin \varphi_{a}\left(1+\sin \varphi_{b}\right)}{\sin \varphi_{b}\left(1+\sin \varphi_{a}\right)},
$$

where $\varphi_{b}$ is internal friction angle of pregrouting broken rock; $\varphi_{a}$ is internal friction angle of postgrouting broken rock; $k$ is within $1.01 \sim 1.50$ generally.

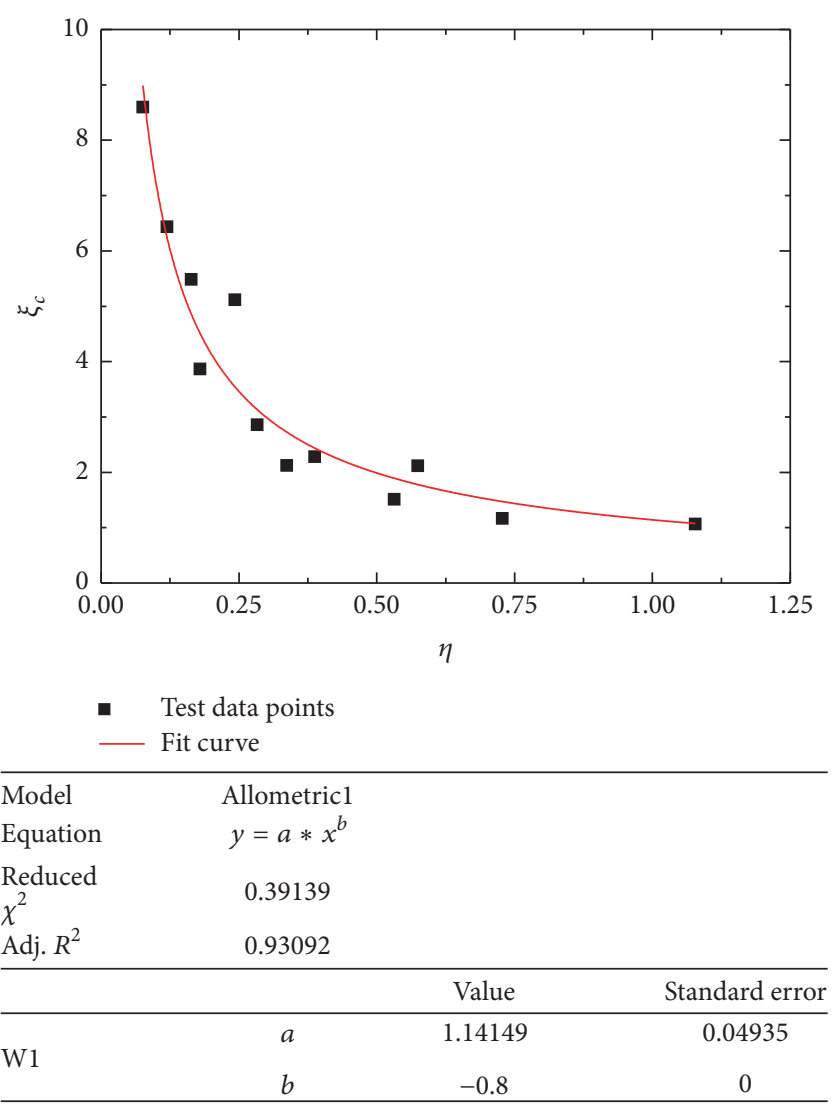

FIGURE 6: The relation between the growth rate of UCS and the relative UCS.

\section{The Growth Rate of UCS of Post- to Pregrouting Broken Rock}

The UCS of broken rock mass postgrouting reinforcement increases. Xu et al. [25] collected 28 days of UCS test data for broken rock mass pre- and postgrouting reinforcement, and analysed variation laws of the growth rate of UCS $\left(\xi_{c}\right)$ with the relative UCS of the initial rock mass $(\eta)$. The relative UCS is a dimensionless parameter that is a ratio of the initial rock mass UCS $\left(S_{c b}\right)$ to the UCS of hardened cement grout concretion after 28 days $\left(q_{c}\right)$. It was proposed as

$$
\eta=\frac{S_{c b}}{q_{c}}
$$

where $\eta$ is the relative UCS of initial rock mass UCS, that is, the ratio of the initial rock mass UCS to the grout concretion $\mathrm{UCS} ; q_{c}$ is the UCS of hardened cement grout concretion after 28 days.

The test data in Table 3 are made being dimensionless using (6) and (14). And the results are shown in Table 4 and Figure 6. In Table 4, the UCS is calculated with MohrCoulomb failure criterion (1). Table 4 shows the change of UCS of the broken rock pre- and postgrouting reinforcement and the cement grout concretion for 28 days with broken rock particle sizes and grout water cement ratio. Figure 6 shows that the UCS growth rate of the broken rock postgrouting 
TABLE 4: Test results of growth rate of UCS on broken rock grouting concretion.

\begin{tabular}{|c|c|c|c|c|c|}
\hline \multirow{3}{*}{$\begin{array}{l}\text { Broken rock } \\
\text { type/water cement } \\
\text { ratio of grout }\end{array}$} & \multicolumn{3}{|c|}{ UCS } & \multirow[b]{2}{*}{$\eta$} & \multirow[b]{2}{*}{$\xi_{c}$} \\
\hline & $\begin{array}{l}\text { Broken rock } \\
\text { grouting } \\
\text { concretion } \\
S_{c a} / \mathrm{MPa}\end{array}$ & $\begin{array}{l}\text { Cement grout } \\
\text { concretion } \\
q_{c} / \mathrm{MPa}\end{array}$ & $\begin{array}{c}\text { Original Broken } \\
\text { rock } \\
S_{c b} / \mathrm{MPa}\end{array}$ & & \\
\hline & $\begin{array}{c}2 c \cos \varphi /(1- \\
\sin \varphi)\end{array}$ & $\begin{array}{c}2 c \cos \varphi /(1- \\
\sin \varphi)\end{array}$ & $\begin{array}{c}2 c \cos \varphi /(1- \\
\sin \varphi)\end{array}$ & $S_{c b} / q_{c}$ & $\left(S_{c a}-S_{c b}\right) / S_{c b}$ \\
\hline $\mathrm{F} / 0.7$ & 8.351 & 11.477 & 0.870 & 0.076 & 8.599 \\
\hline $\mathrm{F} / 0.9$ & 6.471 & 7.265 & 0.870 & 0.120 & 6.437 \\
\hline $\mathrm{F} / 1.1$ & 5.644 & 5.311 & 0.870 & 0.164 & 5.487 \\
\hline $\mathrm{F} / 1.3$ & 5.320 & 3.585 & 0.870 & 0.243 & 5.114 \\
\hline $\mathrm{M} / 0.7$ & 10.014 & 11.477 & 2.059 & 0.179 & 3.864 \\
\hline M/0.9 & 7.940 & 7.265 & 2.059 & 0.283 & 2.856 \\
\hline $\mathrm{M} / 1.1$ & 6.752 & 5.311 & 2.059 & 0.388 & 2.279 \\
\hline $\mathrm{M} / 1.3$ & 6.420 & 3.585 & 2.059 & 0.574 & 2.118 \\
\hline $\mathrm{R} / 0.7$ & 12.059 & 11.477 & 3.864 & 0.337 & 2.120 \\
\hline $\mathrm{R} / 0.9$ & 9.694 & 7.265 & 3.864 & 0.532 & 1.509 \\
\hline $\mathrm{R} / 1.1$ & 8.378 & 5.311 & 3.864 & 0.728 & 1.168 \\
\hline $\mathrm{R} / 1.3$ & 7.981 & 3.585 & 3.864 & 1.078 & 1.065 \\
\hline
\end{tabular}

reinforcement varies with the relative UCS of the original broken rock.

From Figure 6, we find that a correlation between UCS growth rate $\left(\xi_{c}\right)$ for broken rock postgrouting reinforcement and relative UCS $(\eta)$ for broken rock is obvious. The relationship can be expressed as follows using fitting method.

$$
\xi_{c}=1.14 \eta^{-0.8}
$$

$$
\text { (Correlation coefficient } \left.R^{2}=0.9309\right) \text {. }
$$

\section{The Growth Rate of Post- to Pregrouting Broken Rock Mass Shear Strength}

The empirical formula for estimating the internal friction angle of broken rock mass with RMR was presented by Aydan and Kawamoto [22] as follows:

$$
\varphi_{b}=\frac{\pi(20+0.5 \mathrm{RMR})}{180}=\frac{\pi}{9}+\frac{\pi}{360} \mathrm{RMR} \text { (radian) } .
$$

Then the internal friction angle of the rock mass postgrouting reinforcement is

$$
\begin{aligned}
\varphi_{a} & =\frac{\pi}{9}+\frac{\pi}{360}(\mathrm{RMR}+\Delta \mathrm{RMR}) \\
& =\varphi_{b}+\frac{\pi}{360} \Delta \mathrm{RMR} \text { (radian) } .
\end{aligned}
$$

The growth rate of internal friction coefficient for post- to pregrouting broken rock mass can be determined from (9), (16), and (17):

$$
\xi_{f}=\frac{\tan \varphi_{a}-\tan \varphi_{b}}{\tan \varphi_{b}}=\frac{\tan \left(\varphi_{b}+\pi \Delta \mathrm{RMR} / 360\right)}{\tan \varphi_{b}}-1 .
$$

In addition, the growth rate of cohesion for post- to pregrouting broken rock mass is calculated from (12):

$$
\xi_{\mathrm{coh}}=\frac{k\left(\xi_{c}+1\right)}{\xi_{f}+1}-1
$$

\section{The Expression of the Growth Value of RMR for Post- to Pregrouting Broken Rock Mass}

The empirical formula for predicting the UCS of broken rock mass with RMR was presented by Masada and Han [23]:

$$
S_{c b}=0.0016 \mathrm{RMR}^{2.5}(\mathrm{MPa})
$$

The UCS of broken rock mass postgrouting is as follows.

$$
S_{c a}=0.0016(\mathrm{RMR}+\Delta \mathrm{RMR})^{2.5}(\mathrm{MPa}) .
$$

Based on (6), (20), and (21), the expression of the growth rate of UCS for post- to pregrouting broken rock mass is as follows:

$$
\begin{aligned}
\xi_{c} & =\frac{S_{c a}-S_{c b}}{S_{c b}}=\frac{(\mathrm{RMR}+\Delta \mathrm{RMR})^{2.5}}{\mathrm{RMR}^{2.5}}-1 \\
& =\left(1+\frac{\Delta \mathrm{RMR}}{\mathrm{RMR}}\right)^{2.5}-1 .
\end{aligned}
$$

So, the growth value of RMR for post- to pregrouting broken rock mass from (22) and (15) is determined as follows:

$$
\begin{aligned}
\Delta \mathrm{RMR} & =\left[\left(\xi_{c}+1\right)^{0.4}-1\right] \mathrm{RMR} \\
& =\left[\left(1.14 \eta^{-0.8}+1\right)^{0.4}-1\right] \mathrm{RMR} .
\end{aligned}
$$




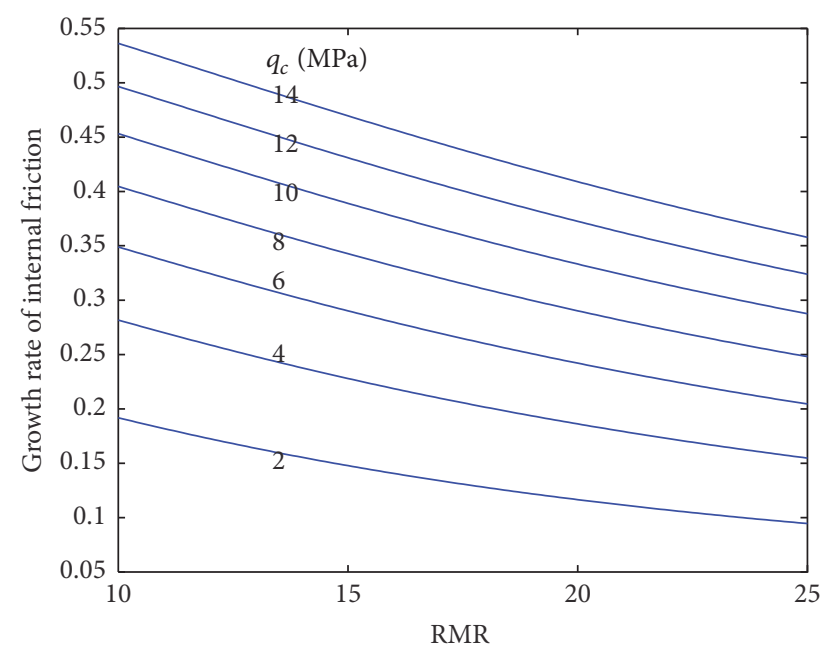

FIGURE 7: The influence of RMR of pregrouting broken rock mass and UCS of grout concretion $\left(q_{c}\right)$ on the growth rate of internal friction coefficient for post- to pregrouting broken rock mass.

\section{Analyses of Strength Growth Rates for Post- to Pregrouting Broken Rock Mass}

The final strength and strength improvement of broken rock mass postgrouting reinforcement are dependent on a range of factors including grouting materials, grouting pressure, grouting duration, extent of fracturing, and the permeation coefficient. The most important factors are grouting quality and pregrouting rock mass quality. The grouting quality may be characterised by the UCS of grout concretion $\left(q_{c}\right)$, while the initial rock mass quality may be characterised by RMR. When $q_{c}$ is from $5 \mathrm{MPa}$ to $40 \mathrm{MPa}$, the RMR ranges from 10 to 40 .

7.1. Influences of RMR and UCS of Grout Concretion on Shear Strength Growth Rates. The UCS growth rate for pre- to postgrouting broken rock mass can be determined using (15) and (20) when RMR and $q_{c}$ are known. $\Delta$ RMR can be determined from (23). The growth rate of internal friction coefficient and the growth rate of cohesion which can be determined from (18) and (19) are shown in Figures 7 and 8.

These figures demonstrate that initial rock and grouting quality strongly influence the growth rate of shear strength parameters for grouted broken rock mass.

The effectiveness of grouting reinforcement has an inverse relationship with rock mass quality. Detailed results are as follows:

(i) The growth rates of shear strength parameters decrease relatively sharply with initial RMR increase and gradually slow to a constant rate across higher RMR values.

(ii) The growth rates of shear strength parameters increase with the increase of UCS of grout concretion after 28 days $\left(q_{c}\right)$. This trend is clearer for low values of RMR.

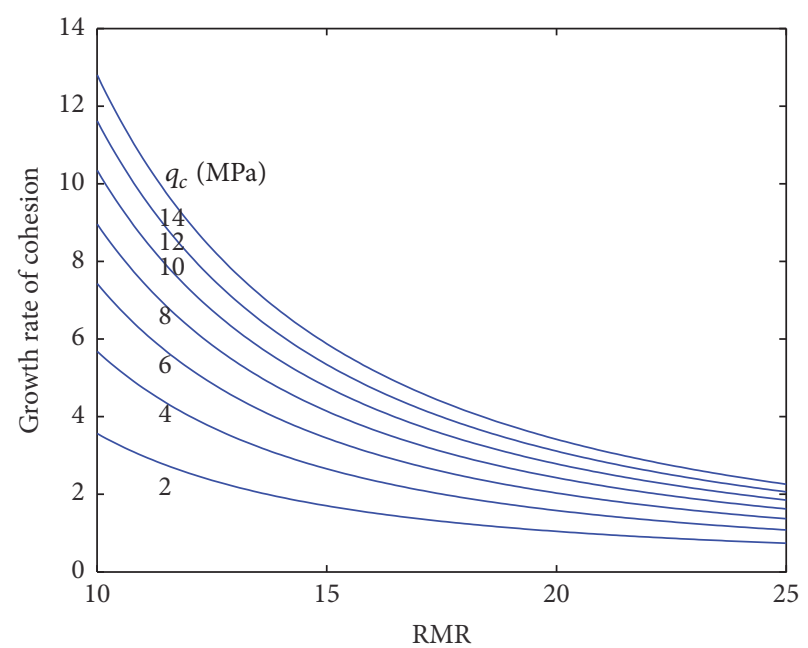

FIGURE 8: The influence of RMR of pregrouting broken mass and UCS of grout concretion $\left(q_{c}\right)$ on the growth rate of cohesion for postto pregrouting broken rock mass.

(iii) The growth rate of cohesion is much higher than that of internal friction coefficient under the same conditions. The growth rate of internal friction coefficient is below 0.4 for RMR greater than 10 and $q_{c}$ less than 14 while the growth rate of cohesion is greater than 1 generally for RMR less than 20 and $q_{c}$ greater than $2 \mathrm{MPa}$.

7.2. Influences of RMR and UCS of Grout Concretion on Growth Rates of UCS and AUTS. The growth of UCS and AUTS for broken rock mass postgrouting can be determined from (11) and (22) and seen in Figures 9 and 10. These figures demonstrate that initial rock mass and grouting quality also have a great influence on the growth rates of UCS and AUTS for pre- to postgrouting broken rock mass. These growth rate values are much higher when the rock mass quality is poor and decrease with an increase of RMR. Detailed conclusions are as follows.

(i) The growth rates of UCS and AUTS rapidly decrease with an increase of RMR and gradually smooth out towards higher RMR values.

(ii) The growth rates of UCS and AUTS increase with an increase of UCS of grout concretion after 28 days $\left(q_{c}\right)$. Growth rate is much higher when the rock mass quality level is low.

(iii) The growth rate of UCS is always greater than that of AUTS under the same conditions.

\section{Verification}

According to the definition of the growth rates of cohesion and internal friction angle with (8) and (9), the test results of the growth rate of the shear strength parameters for broken rock postgrouting reinforcement can be obtained from Tables 3 and 4 , as shown in Table 5. 
TABLE 5: Test results of growth rate of shear strength parameters for broken rock grouting reinforcement.

\begin{tabular}{|c|c|c|c|c|c|c|c|}
\hline \multirow{3}{*}{$\begin{array}{l}\text { Broken rock } \\
\text { type/water cement } \\
\text { ratio of grout }\end{array}$} & \multirow{3}{*}{$\begin{array}{c}\eta \\
S_{c b} / q_{c}\end{array}$} & \multicolumn{4}{|c|}{ Shear strength parameters } & \multirow{3}{*}{$\begin{array}{c}\xi_{\mathrm{coh}}= \\
\left(c_{a}-c_{b}\right) / c_{b}\end{array}$} & \multirow{3}{*}{$\begin{array}{c}\xi_{f}= \\
\left(f_{a}-f_{b}\right) / f_{b}\end{array}$} \\
\hline & & \multicolumn{2}{|c|}{ Broken rock grouting concretion } & \multicolumn{2}{|c|}{ Original broken rock } & & \\
\hline & & $c_{a} / \mathrm{MPa}$ & $f_{a}$ & $c_{b} / \mathrm{MPa}$ & $f_{b}$ & & \\
\hline $\mathrm{F} / 0.7$ & 0.076 & 2.381 & 0.592 & 0.291 & 0.413 & 7.182 & 0.433 \\
\hline $\mathrm{F} / 0.9$ & 0.120 & 1.930 & 0.540 & 0.291 & 0.413 & 5.632 & 0.308 \\
\hline $\mathrm{F} / 1.1$ & 0.164 & 1.694 & 0.533 & 0.291 & 0.413 & 4.8213 & 0.291 \\
\hline $\mathrm{F} / 1.3$ & 0.243 & 1.625 & 0.513 & 0.291 & 0.413 & 4.584 & 0.242 \\
\hline $\mathrm{M} / 0.7$ & 0.179 & 2.616 & 0.696 & 0.634 & 0.504 & 3.126 & 0.381 \\
\hline $\mathrm{M} / 0.9$ & 0.283 & 2.140 & 0.658 & 0.634 & 0.504 & 2.375 & 0.306 \\
\hline $\mathrm{M} / 1.1$ & 0.388 & 1.834 & 0.649 & 0.634 & 0.504 & 1.8934 & 0.288 \\
\hline $\mathrm{M} / 1.3$ & 0.574 & 1.782 & 0.623 & 0.634 & 0.504 & 1.811 & 0.236 \\
\hline $\mathrm{R} / 0.7$ & 0.337 & 2.759 & 0.864 & 1.039 & 0.661 & 1.655 & 0.307 \\
\hline $\mathrm{R} / 0.9$ & 0.532 & 2.299 & 0.817 & 1.039 & 0.661 & 1.213 & 0.236 \\
\hline $\mathrm{R} / 1.1$ & 0.728 & 1.999 & 0.809 & 1.039 & 0.661 & 0.924 & 0.224 \\
\hline $\mathrm{R} / 1.3$ & 1.078 & 1.930 & 0.792 & 1.039 & 0.661 & 0.858 & 0.198 \\
\hline
\end{tabular}

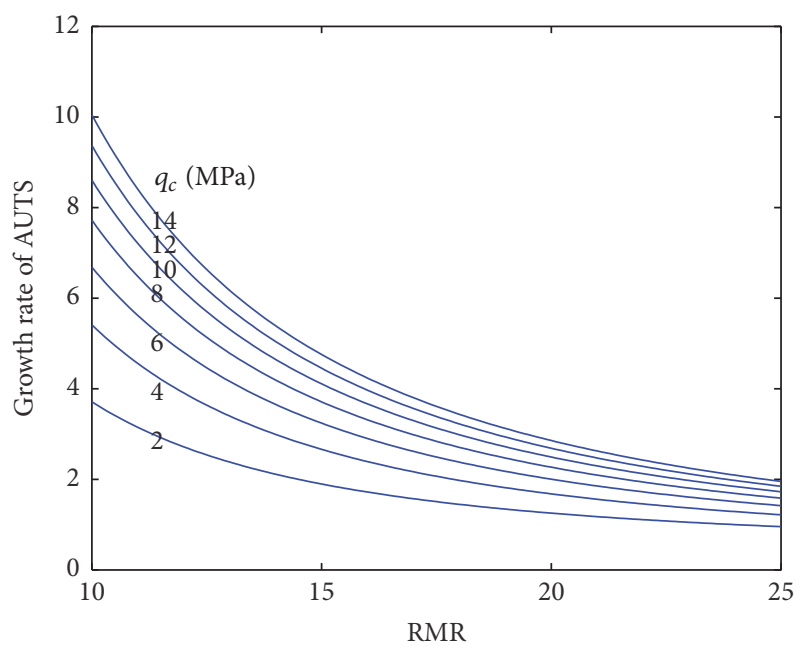

FIGURE 9: The Influence of RMR of pregrouting broken rock mass and UCS of grout concretion $\left(q_{c}\right)$ on the growth rate of AUTS for post- to pregrouting broken rock mass.

In this paper, three types of broken rock (F, M, and $\mathrm{R}$ ) are used. Their UCS values are $0.870,2.059$, and $3.864 \mathrm{MPa}$, respectively, from Table 4 . According to (20), the corresponding values of RMR on the three original broken rocks are calculated as 17.531, 12.421, and 22.551. When the UCS of the cement grout concretion was changed within $2 \mathrm{MPa} \sim$ $14 \mathrm{MPa}$ (approximately corresponding to water cement ratio from 1.84 to 0.62 ), the relative strength for the three-type original broken rock is corresponding to $0.435 \sim 0.062,1.030 \sim$ 0.147 , and 1.932 0.276, respectively. We can get the growth of RMR from formula (23) for broken rock postgrouting reinforcement. Therefore, we can obtain the changing curves of the friction coefficient growth rate (see Figure 11) by formula (18) and the change curves of cohesion growth rate (see Figure 12) by formula (19) with the values of relative UCS of three-type broken rocks.

It can be shown from Figure 11 that there is a good agreement between the theoretical curves and test points

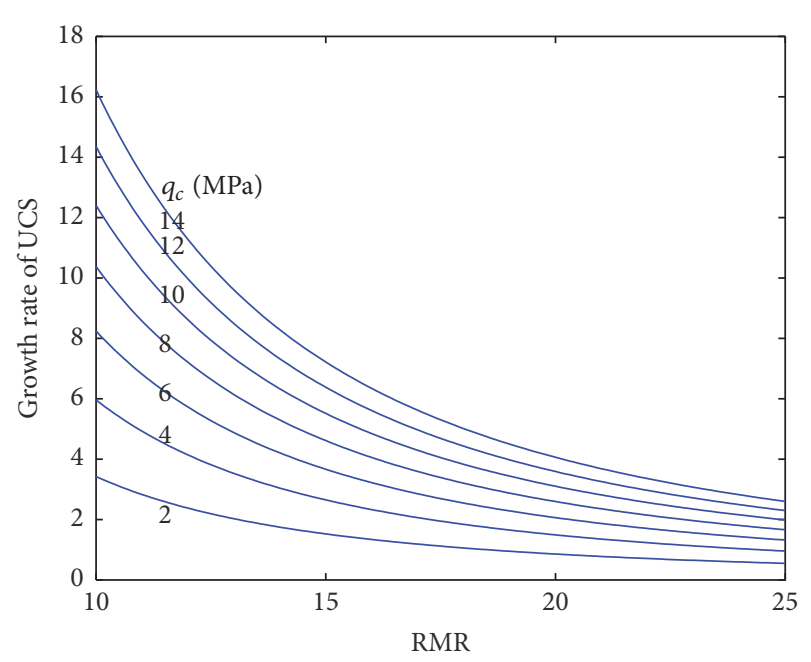

FIGURE 10: The influence of RMR of pregrouting broken rock mass and UCS of grout concretion $\left(q_{c}\right)$ on the growth rate of UCS for postto pregrouting broken rock mass.

on the cohesion growth rate of broken rock postgrouting reinforcement with the relative UCS. The three theoretical curves are among the test points.

It can be seen from Figure 12 that there is also a good agreement between the theoretical curves and test points on the growth rate of the friction coefficient for the broken rock postgrouting reinforcement. The distribution law of three theoretical curves is the same as the test data. The finer the particle of broken rock, the smaller the relative error between theoretical and test on broken rock postgrouting reinforcement.

It is shown by analyzing Figures 11 and 12 intuitively that the theoretical method to estimate the strength growth rate of broken rock postgrouting reinforcement established in this paper is reasonable and provides a new analysis approach for the design of engineering grouting reinforcement. 


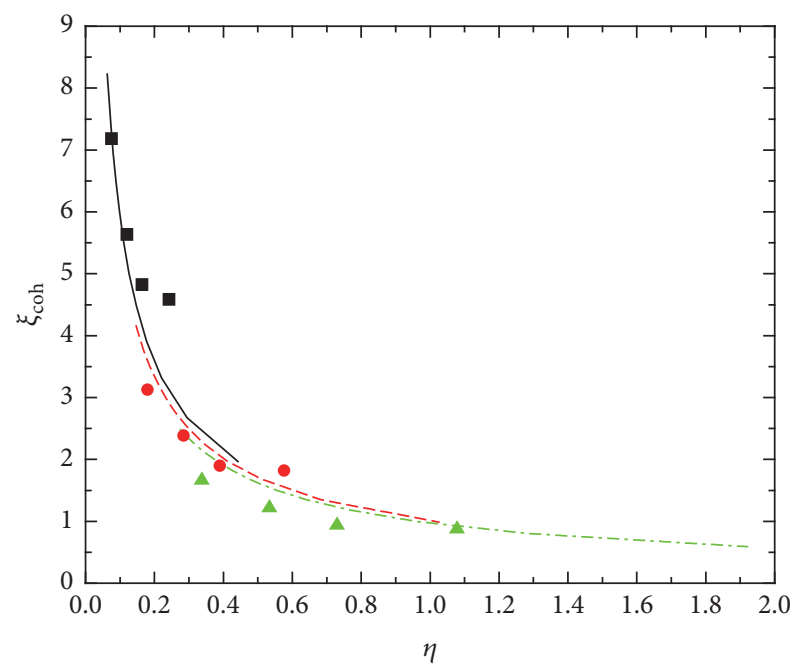

$\begin{array}{ll}\text { Theory curves } & \text { Test points } \\ -S_{c b}=0.87 \mathrm{MPa} & \text { - } \mathrm{F} \\ ---S_{c b}=2.06 \mathrm{MPa} & -\mathrm{M} \\ --S_{c b}=3.86 \mathrm{MPa} & \Delta \mathrm{R}\end{array}$

FIGURE 11: Comparison between theoretical curves and test points on the cohesive growth rate.

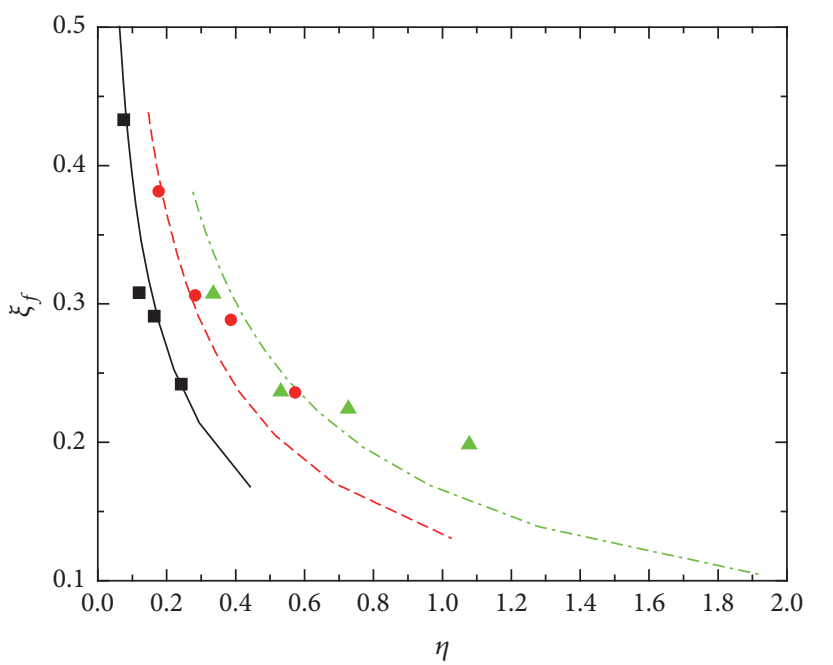

$\begin{array}{ll}\text { Theory curves } & \text { Test points } \\ -S_{c b}=0.87 \mathrm{MPa} & \text { - } \mathrm{F} \\ ---S_{c b}=2.06 \mathrm{MPa} & \bullet \mathrm{M} \\ ---S_{c b}=3.86 \mathrm{MPa} & \Delta \mathrm{R}\end{array}$

FIGURE 12: Comparison between theoretical curves and test points on growth rate of internal friction coefficient.

\section{Concluding Remarks}

This paper presents an investigation into quantifying strength growth estimations of post- to pregrouting broken rock. Using self-developed indoor pressure-grouting devices, we make cube test blocks of the different water cement ratio grouting into different particle sizes broken rock, having 95 of 19 groups in all. Five test schemes are developed to test the shear strength. They test, respectively, the shear strengths of grout concretion with different water cement ratio, of original broken rock of different particle size, and of fine, medium, and coarse particle broken rock grouting reinforcement concretion under different water cement ratio. The cohesion and internal friction coefficient of each group are obtained by the direct shear test. This paper presents a quantitative calculation method for predicting the strength growth of grouted broken rock mass. Relational equations were developed to investigate the relationship between the growth rates of uniaxial compressive strength (UCS). The relational equations between the growth rates of UCS, AUTS, the internal friction coefficient, and broken rock mass cohesion are determined based on the Mohr-Coulomb strength criterion under low-level stress. Expressions for the growth rate of the internal friction coefficient and UCS for grouted broken rock and RMR progression throughout grouting $(\triangle \mathrm{RMR})$ have been developed using the empirical equations of Aydan [12,13]. Using test UCS data, the empirical relational expression between the growths rate of UCS for post- to pregrouting broken rock and the UCS of grout concretion has been determined. The results show that initial rock quality and grouting quality have a significant influence on the strength growth rate of rock mass, UCS, AUTS, internal friction coefficient, and broken rock mass cohesion. The strength growth rates of grouted broken rock mass decrease with increasing of initial RMR and increase with increasing of UCS of grout concretion. The growth rate of UCS is always greater than AUTS under the same conditions. The growth rate of cohesion is much higher than that of internal friction coefficient for the same conditions. The comparative analysis shows that the theoretical results of change rules on growth rate change of the cohesion and the internal friction coefficient for broken rock postgrouting reinforcement with the relative UCS are basically the same as the test rules. These findings are important for the engineered design of broken rock mass grouting reinforcement. The RMR-based method to predict the mechanical parameters of broken rock mass grouting reinforcement and the derived equations can be used effectively for engineering design of various broken rock mass engineering and for the determination of parameters in numerical analysis, which will reduce the calculation error. Based on previous studies [23, 24], RMR and Mohr-Coulomb parameters can be converted into GSI index, Q system, and Hoek-Brown parameters by further research. The selfdeveloped pressure-grouting device allows the grouting test to be carried out in the laboratory and is simple in structure and easy to operate. It is worth to be extended to more geotechnical grouting test.
Abbreviations
$c$ : Cohesion (MPa)
$\varphi$ : Internal friction angle
$f$ : Internal friction coefficient
$\sigma_{n}$ : Normal stress acting on the failure plane
$\tau_{m}$ : Maximum shear stress acting on the failure plane
$\sigma_{1}$ : Maximum principal stress in failure
$\sigma_{3}$ : Minimum principal stress in failure
$S_{c}$ : Uniaxial compressive strength (UCS) 


$\begin{array}{ll}S_{t}: & \begin{array}{l}\text { Absolute value of uniaxial tensile strength } \\ \text { (AUTS) }\end{array} \\ \alpha: & \text { Ratio of the AUTS to the UCS } \\ \xi_{c}: & \text { UCS growth rate } \\ \Delta S_{c}: & \text { Growth value of UCS } \\ S_{c b}: & \text { UCS of pre-grouting broken rock } \\ S_{c a}: & \text { UCS of post-grouting broken rock } \\ \xi_{t}: & \text { AUTS growth rate } \\ \Delta S_{t}: & \text { Growth value of AUTS } \\ S_{t b}: & \text { AUTS of pregrouting broken rock } \\ S_{t a}: & \text { AUTS of postgrouting broken rock } \\ \xi_{c o h}: & \text { Cohesion growth rate } \\ \Delta c: & \text { Growth value of the cohesion } \\ c_{b}: & \text { Cohesion of pregrouting broken rock } \\ c_{a}: & \text { Cohesion of postgrouting broken rock } \\ \xi_{f}: & \text { Growth rate of internal friction coefficient } \\ \Delta f: & \text { Growth value of internal friction coefficient } \\ f_{b}: & \text { Internal friction coefficient of pregrouting } \\ & \text { broken rock }\end{array}$

\section{Conflicts of Interest}

The authors declare that they have no conflicts of interest regarding the publication of this paper.

\section{Acknowledgments}

The authors would like to thank Natural Science Foundation of Jiangsu Province of China (BK20141067) for their financial support.

\section{References}

[1] G. Lombardi, "Grouting of rock masses. Grouting and ground treatment," in Proceedings of the 3rd International Conference on Grouting and Ground Treatment, vol. GSP120, pp. 164-197, ASCE, New Orleans, La, USA, February 2003.

[2] R. Glossop, "The Invention and Development of Injection Processes Part I: 1902-1850," Géotechnique, vol. 10, no. 3, pp. 91$100,1960$.

[3] S. J. Li, X. H. Yang, and X. Z. Li, "Numerical simulation of earth pressure on tunnel considering backfill grouting," Journal of Highway and Transportation Research and Development, vol. 31, no. 11, pp. 96-102, 2014.

[4] H. Youn and F. Tonon, "Numerical analysis on post-grouted drilled shafts: a case study at the Brazo River Bridge, TX," Computers \& Geotechnics, vol. 37, no. 4, pp. 456-465, 2010.

[5] E. A. Sellountou, The effects of construction on the behavior of Augered-Cast-in Place (ACIP) piles in Texas Gulf Coast Soil [Ph.D. thesis], Department of Civil and Environmental Engineering, University of Houston, 2004.

[6] F. Wang, C. Zhang, S. Wei, X. Zhang, and S. Guo, "Whole section anchor-grouting reinforcement technology and its application in underground roadways with loose and fractured surrounding rock," Tunnelling \& Underground Space Technology, vol. 51, pp. 133-143, 2016.

[7] H. Z. He and X. H. Wang, "Study on parameters of grouting reinforced Rim during undersea tunnel," Technology of Highway and Transport, no. 5, pp. 99-102, 2008.

[8] M. Sharghi, H. Chakeri, and Y. Ozcelik, "Investigation into the effects of two component grout properties on surface settlements," Tunnelling and Underground Space Technology, vol. 63, pp. 205-216, 2017.

[9] H. L. Dai, X. Wang, G. X. Xie, and X. Y. Wang, "Theoretical model and solution for the rheological problem of anchorgrouting a soft rock tunnel," International Journal of Pressure Vessels and Piping, vol. 81, no. 9, pp. 739-748, 2004.

[10] Y. Dai, W. Chen, H. Tian, J. Yang, X. Meng, and X. Deng, "Study of large deformation and support measures of daliang tunnel with soft surrounding rockmass," Chinese Journal of Rock Mechanics and Engineering, vol. 34, no. 2, pp. 4149-4156, 2015.

[11] ISRM, "International society for rock mechanics commission on rock grouting," International Journal of Rock Mechanics and Mining Science \& Geomechanics Abstracts, vol. 33, no. 8, pp. 803847, 1996.

[12] K. Kikuchi, T. Igari, Y. Mito, and S. Utsuki, "In situ experimental studies on improvement of rock masses by grouting treatment," International journal of rock mechanics and mining sciences \& geomechanics abstracts, vol. 34, no. 3-4, pp. 138.el-138.e14, 1997.

[13] M. J. Yang and N. Zhang, "Study on the intrinsic model of broken rockmass after grouting reinforcement," Metal Mine, no. 5, pp. 11-14, 1998.

[14] C. Butrón, M. Axelsson, and G. Gustafson, "Silica sol for rock grouting: laboratory testing of strength, fracture behaviour and hydraulic conductivity," Tunnelling and Underground Space Technology, vol. 24, no. 6, pp. 603-607, 2009.

[15] A. Zolfaghari, A. Sohrabi Bidar, M. R. Maleki Javan, M. Haftani, and A. Mehinrad, "Evaluation of rock mass improvement due to cement grouting by Q-system at Bakhtiary dam site," International Journal of Rock Mechanics and Mining Sciences, vol. 74, pp. 38-44, 2015.

[16] J. Tinoco, A. G. Correia, and P. Cortez, "A data mining approach for jet grouting uniaxial compressive strength prediction," in Proceedings of the World Congress on Nature and Biologically Inspired Computing (NaBIC '09), pp. 553-558, December 2009.

[17] R. Akan, S. N. Keskin, and S. Uzundurukan, "Multiple Regression Model for the Prediction of Unconfined Compressive Strength of Jet Grout Columns," Procedia Earth and Planetary Science, vol. 15, pp. 299-303, 2015.

[18] H. Zhou, "Numerical simulation of the relationship of bearing capacity of post-grouting bored pile and grouting parameters," Industrial Construction, vol. 35, no. 9, pp. 60-63, 2005.

[19] Z. T. Bieniawski, Engineering Rock Mass Classifications, Science Press, New York, NY, USA, 1989. 
[20] S. Swedenberg and L.-O. Dahlström, "Rock mechanics effects of cement grouting in hard rock masses," in Proceedings of the 3rd International Conference: Grouting and Ground Treatment, pp. 1089-1102, February 2003.

[21] Ö. Aydan, R. Ulusay, and T. Kawamoto, "The assessment of rock mass strength for underground excavations," in Proceedings of the 36th US Rock Mechanics Symposium, pp. 777-786, New York, NY, USA, 1997.

[22] Ö. Aydan and T. Kawamoto, "The assessment of mechanical properties of rock masses through RMR rock classification system," in Proceedings of the ISRM International Symposium (GeoEng '00), vol. UW0926, Melbourne, Australia, 2000.

[23] T. Masada and X. Han, "Rock mass classification system: transition from RMR to GSI," Research Report, Ohio Research Institute for Transportation and the Environment, 2013.

[24] E. Hoek, "Estimating Mohr-Coulomb friction and cohesion values from the Hoek-Brown failure criterion," International Journal of Rock Mechanics and Mining Sciences \& Geomechanics Abstracts, vol. 27, no. 3, pp. 227-229, 1990.

[25] H.-F. Xu, H.-S. Geng, C.-F. Li, W. Chen, and C. Wang, "Estimating strength of grouting reinforced bodies in broken rock mass," Yantu Gongcheng Xuebao/Chinese Journal of Geotechnical Engineering, vol. 35, no. 11, pp. 2018-2022, 2013.

[26] H.-F. Xu, H.-S. Geng, W.-D. Li, and C. Wang, "Theory of strength increment of grouting-reinforced bodies for broken rock mass based on BQ," Chinese Journal of Geotechnical Engineering, vol. 36, no. 6, pp. 1147-1151, 2014.

[27] J. C. Jaeger, N. G. W. Cook, and R. W. Zimmerman, Fundamentals of Rock Mechanics, Blackwell, London, UK, 4th edition, 2007. 


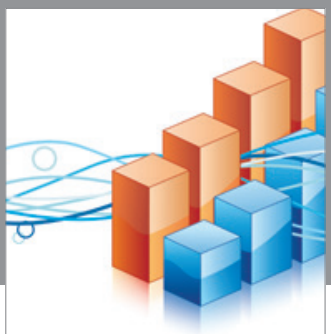

Advances in

Operations Research

vatem alat4

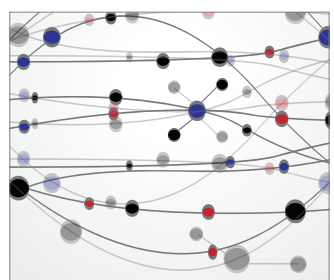

\section{The Scientific} World Journal
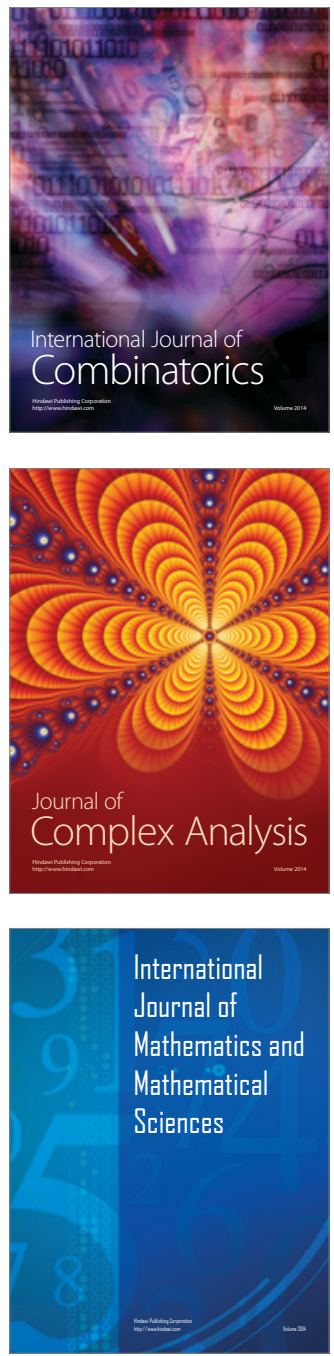
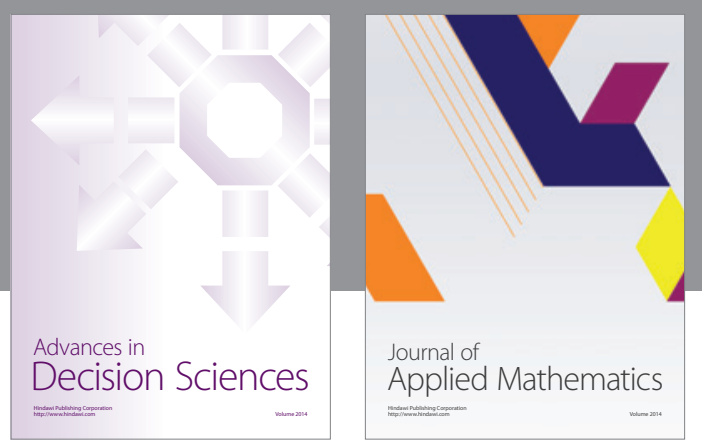

Algebra

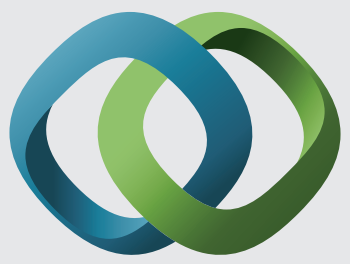

\section{Hindawi}

Submit your manuscripts at

https://www.hindawi.com
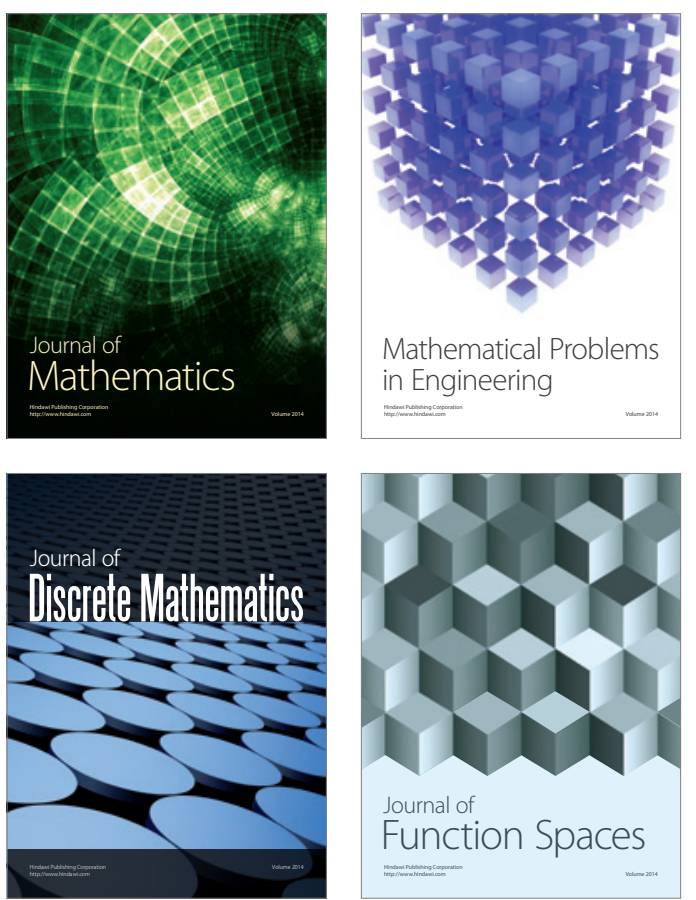

Mathematical Problems in Engineering
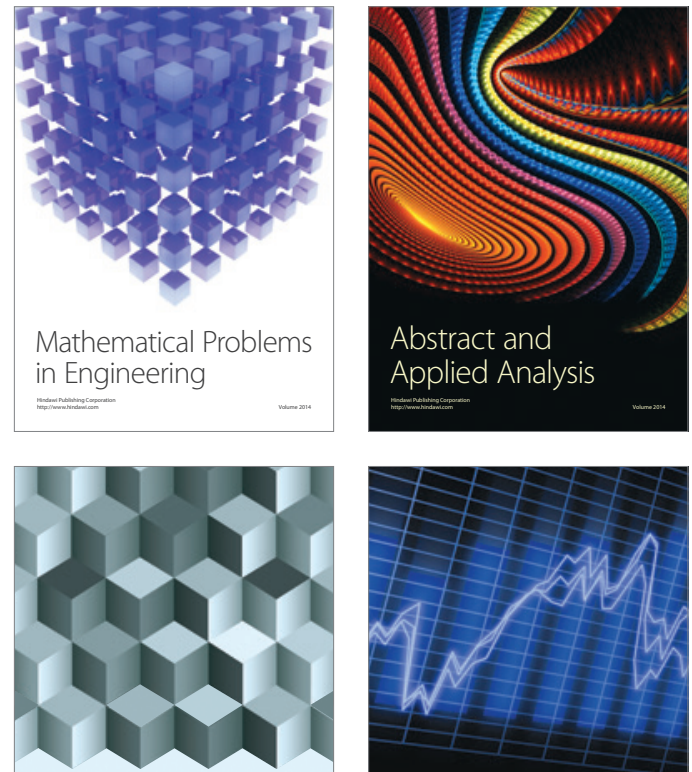

Journal of

Function Spaces

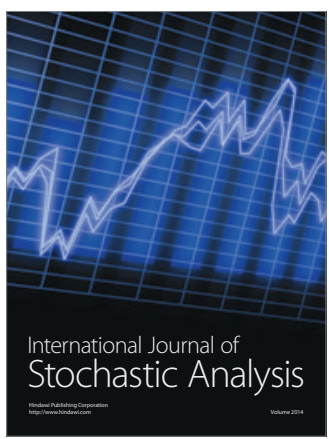

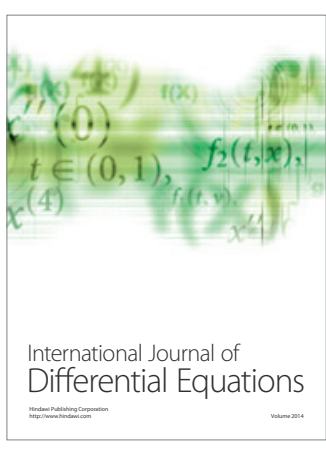
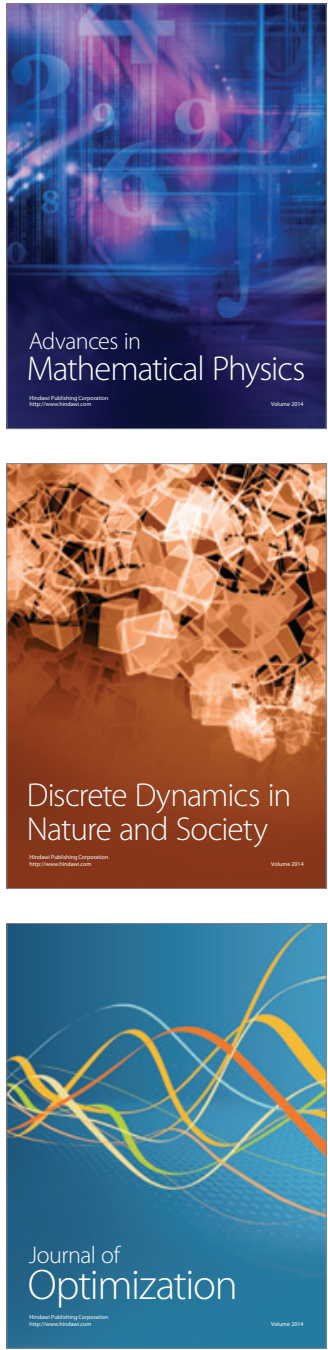